\title{
Identification of a High-Risk Group of New-Onset Cardiovascular Disease in Occupational Drivers by Analyzing Heart Rate Variability
}

\author{
Ying-Chuan Wang ${ }^{1,2}{ }^{(}$, Chung-Ching Wang ${ }^{1,2}\left(\mathbb{D}\right.$, Ya-Hsin $\mathrm{Yao}^{3}$ and Wei-Te $\mathrm{Wu}^{4,5,6, *}$ \\ 1 Division of Family Medicine, Department of Family and Community Medicine, Tri-Service General Hospital, \\ National Defense Medical Center, Taipei 114, Taiwan; popoga96@gmail.com (Y.-C.W.); \\ bigching@gmail.com (C.-C.W.) \\ 2 Division of Occupational Medicine, Department of Family and Community Medicine, Tri-Service General \\ Hospital, National Defense Medical Center, Taipei 114, Taiwan \\ 3 School of Medicine, National Defense Medical Center, Taipei 114, Taiwan; yamcom13579@gmail.com \\ 4 National Institute of Environmental Health Sciences, National Health Research Institutes, Miaoli 350, Taiwan \\ 5 Institute of Environmental and Occupational Health Sciences, National Yang Ming Chiao Tung University, \\ Taipei 112, Taiwan \\ 6 Department of Healthcare Administration, Asia University, Taichung 413, Taiwan \\ * Correspondence: popoga95@gmail.com
}

check for updates

Citation: Wang, Y.-C.; Wang, C.-C.; Yao, Y.-H.; Wu, W.-T. Identification of a High-Risk Group of New-Onset

Cardiovascular Disease in

Occupational Drivers by Analyzing Heart Rate Variability. Int. J. Environ. Res. Public Health 2021, 18, 11486. https://doi.org/10.3390/ ijerph182111486

Academic Editor: Paul B. Tchounwou

Received: 1 October 2021

Accepted: 29 October 2021

Published: 31 October 2021

Publisher's Note: MDPI stays neutral with regard to jurisdictional claims in published maps and institutional affiliations.

Copyright: (c) 2021 by the authors. Licensee MDPI, Basel, Switzerland. This article is an open access article distributed under the terms and conditions of the Creative Commons Attribution (CC BY) license (https:// creativecommons.org/licenses/by/ $4.0 /)$.

\begin{abstract}
Purpose: This cohort study evaluated the effectiveness of noninvasive heart rate variability (HRV) analysis to assess the risk of cardiovascular disease over a period of 8 years. Methods: Personal and working characteristics were collected before biochemistry examinations and $5 \mathrm{~min}$ HRV tests from the Taiwan Bus Driver Cohort Study (TBDCS) in 2005. This study eventually identified 161 drivers with cardiovascular disease (CVD) and 627 without between 2005 and 2012. Estimation of the hazard ratio was analyzed by using the Cox proportional-hazards model. Results: Subjects with CVD had an overall lower standard deviation of NN intervals (SDNN) than their counterparts did. The SDNN index had a strong association with CVD, even after adjusting for risk factors. Using a median split for SDNN, the hazard ratio of CVD was $1.83(95 \% \mathrm{CI}=1.10-3.04)$ in Model 1 and 1.87 (95\% CI = 1.11-3.13) in Model 2. Furthermore, the low-frequency (LF) index was associated with a risk of CVD in the continuous approach. For hypertensive disease, the SDNN index was associated with increased risks in both the continuous and dichotomized approaches. When the root-mean-square of the successive differences (RMSSDs), high frequency (HF), and LF were continuous variables, significant associations with hypertensive disease were observed. Conclusions: This cohort study suggests that SDNN and LF levels are useful for predicting 8 year CVD risk, especially for hypertensive disease. Further research is required to determine preventive measures for modifying HRV dysfunction, as well as to investigate whether these interventions could decrease CVD risk among professional drivers.
\end{abstract}

Keywords: early monitoring; heart rate variability; cardiovascular diseases; professional bus driver; cohort study

\section{Introduction}

Cardiovascular disease (CVD) is not only the leading cause of death in the world, but also a compensable diseases related to work [1,2]. Since the 1950s, many researchers have studied the occupational issues of professional drivers [3]. Male professional drivers have an elevated morbidity and mortality from myocardial infarction (MI), ischemic heart disease (IHD), coronary heart disease (CHD) [4-6], stroke [7], and arteriosclerosis, according to the brachial-ankle pulse wave velocity [8]. Some studies have indicated that professional drivers have an elevated risk of developing CVD due to a high workload and a psychosocial work environment, due to a highly demanding job, irregular shifts, overtime work, and 
limited meals and rest time [6,9-11]. Professional drivers living with CVD conditions are predisposed to work stress, triggering death by overwork. Therefore, early monitoring of a high-risk CVD group is important to design preventive measures and thus limit further health damage in the workplace.

The examination of heart rate variability (HRV) is a simple, noninvasive, and relatively inexpensive method for an epidemiological study with a large sample size [12-18]. HRV measures specifically reflect vagal activity and have been recommended by the Task Force of the European Society of Cardiology and the North American Society of Pacing and Electrophysiology (1996) [19]. The cardiovascular system is controlled by the nervous system, specifically, the autonomic nervous system (ANS) [18-21]. Table S1 (available as an online Supplementary Material) presents the definitions of HRV measures applied in our research $[22,23]$.

Reduced HRV as a marker of autonomic dysfunction has been shown to be associated with a poor prognosis of CVD, as well as with MI incidence, CVD mortality, and death from other causes in the general population [24-31], Furthermore, decreased HRV at rest is associated with a poor prognosis of CVD [32], and reduced resting HRV is considered a risk marker for future cardiovascular and other stress-related diseases [33].

However, some problems have emerged in this research field, including small sample sizes, incomplete CVD data collection, and poor control for confounders, which have limited the evaluation of the independent predictive effect of HRV, and has not shown a clear causal relationship. Therefore, we adopted a cohort study design to assess the effectiveness of noninvasive HRV analysis to measure professional drivers' autonomic function, and then investigated the relationship between HRV and the 8 year risk of CVDs.

\section{Materials/Subjects and Methods}

\subsection{Study Population}

A Taiwan Bus Drivers Cohort (TBDC) has previously been established [34] for a longitudinal follow-up study. We linked this cohort to Taiwan's National Health Insurance Research Database (NHIRD) to obtain the medical information of these subjects. This study was approved by the Institutional Review Board of the National Health Research Institutes, Taiwan (NIRB File Number: EC1060516-E). The composition and operation of the review committee were established in accordance with the International Conference on Harmonization-Good Clinical Practice (ICH-GCP) guidelines. The authors confirm that all experiments were carried out in accordance with the relevant guidelines and regulations. Informed consent was obtained from all participants. A questionnaire was used to collect basic information and working patterns, including demographic characteristics, work conditions (year of first employment and bus driving experience), lifestyle habits, and job stress assessment. This study adopted a longitudinal design from 2005 to 2012, the questionnaire collected information on basic and working patterns and $\mathrm{HRV}$, and two sets of biochemical measurements were conducted simultaneously (Supplementary Figure S1). This cohort was linked to Taiwan's National Health Insurance Research Database (NHIRD) to obtain the CVD medical information of these subjects.

Figure 1 illustrates the procedures used in this study. The TBDC was created in 2006 and includes 1650 professional drivers from the largest transportation company in Taiwan. The Driving Hours Dataset between 2005 and 2007 was used to exclude subjects with a driving duration of fewer than 100 days $(n=613)$. Then, personal and working characteristics were collected before biochemistry examinations, and HRV tests were performed from 2007 to 2008. We excluded individuals with incomplete questionnaires or laboratory data $(n=249)$. Subsequently, we linked the remaining 788 drivers to the ambulatory care expenditures-by-visits and inpatient expenditures-by-admissions data from the NHIRD. The defining criteria for CVD cases were that bus drivers had had at least five recorded clinical visits within one year due to CVD, or at least one inpatient record because of CVD for the first-listed diagnosis code. The strict criteria increased the sensitivity and decreased the specificity for confirming CVD. We identified 161 drivers with 
CVD (International Classification of Diseases 9th Revision, ICD-9: 390-459) and 627 drivers without CVD from 2005 to 2012. Among the 161 drivers with CVD, 84 had a history of CVD before 2006. Finally, 77 incident CVD cases were defined. Meanwhile, CVD (excluding hypertensive disease) (ICD-9: 391, 392.0, 393-398, 410-414, 416, 420-429), IHD (ICD-9: 410-414), cerebrovascular disease (ICD-9: 430-438), and congestive heart failure (CHF) (ICD-9: 398.91, 422, 425, 428, 402.x1, 404.x1, 404.x3) were analyzed separately.

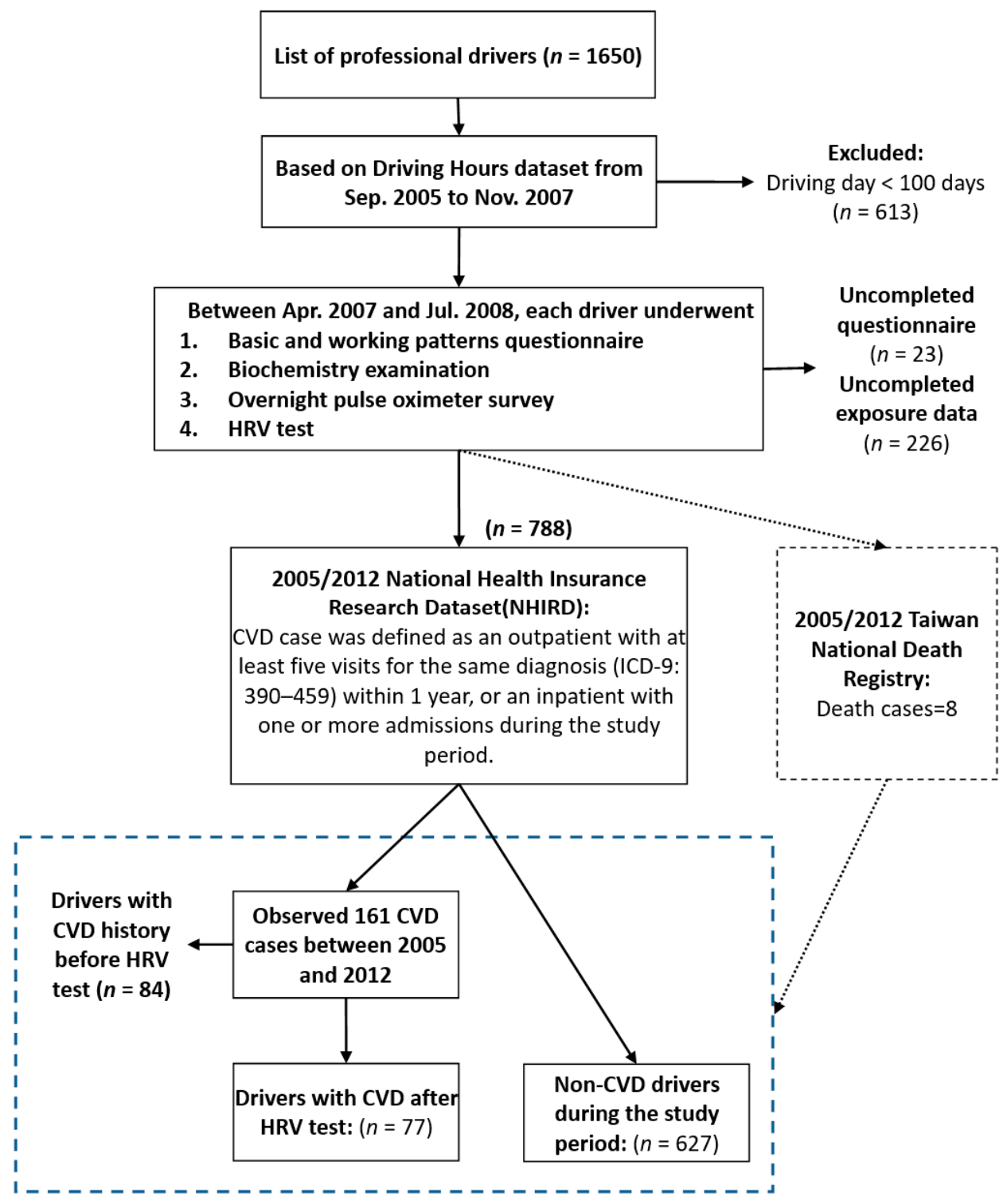

Figure 1. Study flow diagram in the Taiwan Bus Driver Cohort Study.

\subsection{HRV and Biochemical Measurements}

Each participant underwent a blood biochemistry test and noninvasive HRV examination in resting conditions with the ANS Analyzer (Medicore SA-3000P, Jamsil-dong, Songpa-gu, Seoul, Korea). The variability in heart rate over $5 \mathrm{~min}$ was analyzed by the method of time domain and frequency domain. This provided the degree of balance and activity of the ANS. The standard deviation of the normal-to-normal beats interval (SDNN) and the square root of the mean squared differences of successive $\mathrm{N}-\mathrm{N}$ intervals (RMSSD) were used to compare the time domain indexes. Frequency domain methods, including very low frequency (VLF, $0.0033-0.04 \mathrm{~Hz}$ ), low frequency $(\mathrm{LF}, 0.04-0.15 \mathrm{~Hz}$ ), high frequency $(\mathrm{HF}, 0.15-0.4 \mathrm{~Hz})$, and total power $(\mathrm{TP})$ were used to determine the sympathetic 
and parasympathetic heartbeat rate modulations at rest. The physical stress index (PSI) reflected the load and pressure on the heart based on SDNN at the same time [35].

For the determination of total cholesterol (CHOL), this study employed the cholesterol oxidase method on an AU640 analyzer (Beckman Coulter Ltd., High Wycombe, UK). High-density lipoprotein cholesterol (HDL-C) levels were determined using the immunoinhibition method on the AU640 analyzer (Beckman Coulter Ltd., High Wycombe, UK). Triglyceride (TG) concentrations were determined using an enzymatic method on the AU640 analyzer (Beckman Coulter Ltd., High Wycombe, UK). Fasting blood glucose (FG) was conducted using the hexokinase method, also on the AU640 analyzer (Beckman Coulter Ltd., High Wycombe, UK).

\subsection{Statistical Analysis}

Logarithmical transformation was performed to approximate the normal distribution. This study also used a Cox proportional-hazards model to assess the effect of HRV parameters on the risk of CVD (hazard ratios (HRs) and 95\% confidence intervals (CIs)) and to adjust for confounding variables. Standard median splits were used on HRV parameters (the continuous variables) to turn them into dichotomous variables. The risk factors we considered included age, job tenure, shift work, body mass index, drinking, smoking, exercise, and education. Moreover, clinical conditions such as systolic blood pressure, $\mathrm{CHOL}, \mathrm{TG}, \mathrm{HDL}$, and fasting glucose were also considered. Age at first employment ( $\geq 45$ vs. $<45$ years), time since first employment (years), shift work, body mass index (BMI; $>30$ vs. $\leq 30$ ), drinking, smoking, exercise, and education were adjusted in Model 1. Next, we adjusted for clinical conditions, including systolic blood pressure, LnCHOL, LnTG, LnHDL, and Ln (fasting glucose) in Model 2. All analyses were performed using the Statistical Analysis System (SAS) software package (Version 9.3 for Windows; SAS Institute Inc., Cary, NC, USA).

\section{Results}

Demographic characteristics of the bus drivers are presented in Table 1. A total of 788 drivers and 5334.2 person-years were accumulated in this cohort. Almost half of the bus drivers were over 40 years old in their first employment (43.3\%), more than half of the bus drivers $(51.5 \%)$ had over 5 years of driving experience, and almost half were irregular shift-working drivers (47\%). About $16 \%$ of the bus drivers were obese (BMI $\geq 30 \mathrm{~kg} / \mathrm{m}^{2}$ ), more than half of the bus drivers had a smoking habit (57.5\%), and $21.7 \%$ of the bus drivers had a drinking habit.

A comparison of HRV parameters between different cardiovascular diagnostic categories is shown in Table S2 (available as an online Supplementary Material). The cohort of 788 subjects included 49 people with CVD (not including hypertensive disease); 128 people with hypertensive disease; 35 people with IHD; 14 people with cerebrovascular disease; 8 people with diseases of the arteries, arterioles, and capillaries, as well as other diseases of the circulatory system; and 15 people with CHF.

\subsection{HRV Indices and 8-Year CVD Risks}

Table 2 lists the hazard ratios for CVD per single unit increment of HRV parameters (as continuous variables), as well as for dichotomized HRV parameters. For the 788 drivers with a known CVD history, an increased SDNN level had a negative association with the risk of CVD in the continuous approach in both models. The SDNN had a significant hazard ratio (per single unit increment) of 0.67 to 0.70 . Regarding the dichotomized approach with a median split, a low SDNN level was associated with CVD (hazard ratio $=1.47 ; 95 \%$ CI $=1.04-2.07)$ in Model 1 and (1.44; 95\% CI =1.01-2.05) in Model 2. 
Table 1. Baseline characteristics of the study population.

\begin{tabular}{|c|c|c|c|c|}
\hline \multirow{2}{*}{ Variables } & \multicolumn{2}{|c|}{ All Drivers } & \multicolumn{2}{|c|}{ Person Years } \\
\hline & $n$ & $(\%)$ & sum & $(\%)$ \\
\hline Total subjects & 788 & 100.0 & 5334.2 & 100.0 \\
\hline Non-CVD drivers & 627 & 79.6 & 5014.3 & 94.0 \\
\hline CVD drivers $^{a}$ & 161 & 20.4 & 319.9 & 6.0 \\
\hline CVD history before $2006^{a, b}$ & 84 & 10.7 & 11.7 & 0.2 \\
\hline \multicolumn{5}{|l|}{ Age (years) } \\
\hline$<35$ & 87 & 11.0 & 666.5 & 12.5 \\
\hline $35-44$ & 340 & 43.1 & 2417.4 & 45.3 \\
\hline $45-49$ & 199 & 25.3 & 1339.6 & 25.1 \\
\hline$\geq 50$ & 162 & 20.6 & 910.7 & 17.1 \\
\hline \multicolumn{5}{|l|}{ Age at first employment (years) } \\
\hline$\leq 32$ & 175 & 22.2 & 1320.6 & 24.8 \\
\hline $3 \overline{3}-38$ & 272 & 34.5 & 1872.6 & 35.1 \\
\hline$\geq 39$ & 341 & 43.3 & 2141.1 & 40.1 \\
\hline \multicolumn{5}{|l|}{$\begin{array}{c}\text { Time since first employment } \\
\text { (years) }\end{array}$} \\
\hline$\leq 2$ & 150 & 19.0 & 1091.8 & 20.5 \\
\hline $2.1-5$ & 232 & 29.4 & 1647.2 & 30.9 \\
\hline $5.1-8$ & 164 & 20.8 & 1059.9 & 19.9 \\
\hline$>8$ & 242 & 30.7 & 1535.4 & 28.8 \\
\hline \multicolumn{5}{|l|}{ Shift work modes ${ }^{c}$} \\
\hline Day shifts only & 338 & 42.9 & 2264.8 & 42.5 \\
\hline Irregular shift & 370 & 47.0 & 2587.1 & 48.5 \\
\hline Evening and Night shift & 80 & 10.2 & 482.4 & 9.0 \\
\hline \multicolumn{5}{|l|}{ BMI $\left(\mathrm{kg} / \mathrm{m}^{2}\right)$} \\
\hline$<25$ & 299 & 37.9 & 2166.6 & 40.6 \\
\hline $25-29.9$ & 359 & 45.6 & 2361.8 & 44.3 \\
\hline$\geq 30$ & 130 & 16.5 & 805.9 & 15.1 \\
\hline \multicolumn{5}{|l|}{ Marital status } \\
\hline Unmarried & 124 & 15.7 & 919.8 & 17.2 \\
\hline Married & 577 & 73.2 & 3841.7 & 72.0 \\
\hline Others & 87 & 11.0 & 572.7 & 10.7 \\
\hline \multicolumn{5}{|l|}{ Education } \\
\hline$\leq$ Junior high school & 235 & 29.8 & 1556.9 & 29.2 \\
\hline Senior high and vocational school & 498 & 63.2 & 3396.2 & 63.7 \\
\hline University and College & 55 & 7.0 & 381.1 & 7.1 \\
\hline \multicolumn{5}{|l|}{ Cigarette smoking } \\
\hline Current smokers & 276 & 35.0 & 1808.7 & 33.9 \\
\hline Ex-smokers & 54 & 6.9 & 337.4 & 6.3 \\
\hline Never smokers & 453 & 57.5 & 3148.1 & 59.0 \\
\hline Missing & 5 & & & \\
\hline \multicolumn{5}{|l|}{ Alcohol use } \\
\hline Yes & 612 & 77.7 & 4240.5 & 79.5 \\
\hline No & 171 & 21.7 & 1061.3 & 19.9 \\
\hline Missing & 5 & & & \\
\hline \multicolumn{5}{|l|}{ Moderate exercise } \\
\hline Yes & 557 & 70.7 & 3857.0 & 72.3 \\
\hline No & 221 & 28.0 & 1397.3 & 26.2 \\
\hline Missing & 10 & & & \\
\hline
\end{tabular}

a The selection criteria for CVD (ICD-9-CM: 390-459) were at least five clinical visit records within a year or at least one inpatient record; ${ }^{\mathrm{b}}$ drivers who had a CVD history before $2006{ }^{\mathrm{c}}$ based on the Driving Hours Dataset. 
Table 2. Hazard ratios and 95\% confidence intervals for cardiovascular disease by HRV index in the study population.

\begin{tabular}{|c|c|c|c|c|c|c|c|c|c|c|c|c|c|c|c|c|c|}
\hline \multirow[b]{4}{*}{1} & \multirow{4}{*}{$\begin{array}{l}\text { Independent Variables }^{\mathbf{d}} \\
\text { As a continuous (LnSDNN) }\end{array}$} & \multicolumn{8}{|c|}{ All Drivers $(n=788)$} & \multicolumn{8}{|c|}{ Drivers $(n=704)^{a}$} \\
\hline & & \multirow{3}{*}{$\begin{array}{l}\text { HR } \\
0.67\end{array}$} & \multirow{2}{*}{\multicolumn{2}{|c|}{$\begin{array}{l}\text { Model } 1^{b} \\
95 \% \text { CI }\end{array}$}} & \multirow{3}{*}{$\frac{p \text {-Value }}{0.018}$} & \multirow{3}{*}{$\begin{array}{c}\text { HR } \\
0.70\end{array}$} & \multirow{2}{*}{\multicolumn{2}{|c|}{$\begin{array}{l}\text { Model } 2^{\mathrm{c}} \\
95 \% \text { CI }\end{array}$}} & \multirow{3}{*}{$\frac{p \text {-Value }}{0.047}$} & \multirow{3}{*}{$\begin{array}{l}\text { HR } \\
0.57\end{array}$} & \multirow{2}{*}{\multicolumn{2}{|c|}{$\begin{array}{l}\text { Model } 1 \\
95 \% \text { CI }\end{array}$}} & \multirow{3}{*}{$\frac{p \text {-Value }}{0.029}$} & \multirow{3}{*}{$\begin{array}{l}\text { HR } \\
0.56\end{array}$} & \multirow{2}{*}{\multicolumn{2}{|c|}{$\begin{array}{l}\text { Model 2 } \\
\text { 95\% CI }\end{array}$}} & \multirow{3}{*}{$\frac{p \text {-Value }}{0.031}$} \\
\hline & & & & & & & & & & & & & & & & & \\
\hline & & & 0.48 & 0.93 & & & 0.50 & 1.00 & & & 0.35 & 0.95 & & & 0.34 & 0.95 & \\
\hline 2 & $\begin{array}{l}\text { As a categorical } \\
\text { variable: SDNN } \\
(\leq 30 \text { vs. }>30)\end{array}$ & 1.47 & 1.04 & 2.07 & 0.029 & 1.44 & 1.01 & 2.05 & 0.044 & 1.83 & 1.10 & 3.04 & 0.020 & 1.87 & 1.11 & 3.13 & 0.018 \\
\hline 3 & As a continuous (LnRMSSD) & 0.83 & 0.62 & 1.10 & 0.185 & 0.85 & 0.64 & 1.13 & 0.264 & 0.83 & 0.54 & 1.28 & 0.397 & 0.81 & 0.52 & 1.26 & 0.348 \\
\hline 4 & $\begin{array}{c}\text { As a categorical } \\
\text { variable: } \operatorname{RMSSD}(\leq 20 \text { vs. }>20)\end{array}$ & 1.34 & 0.95 & 1.89 & 0.098 & 1.34 & 0.94 & 1.91 & 0.104 & 1.34 & 0.81 & 2.20 & 0.256 & 1.38 & 0.83 & 2.28 & 0.211 \\
\hline 5 & $\begin{array}{c}\text { As a continuous (LnLF) } \\
\text { As a categorical }\end{array}$ & 0.85 & 0.74 & 0.97 & 0.016 & 0.88 & 0.76 & 1.02 & 0.084 & 0.80 & 0.66 & 0.98 & 0.031 & 0.79 & 0.64 & 0.98 & 0.032 \\
\hline 6 & $\begin{array}{l}\text { As a categorical } \\
\text { variable: } \mathrm{LF} \\
(\leq 380 \text { vs. }>380)\end{array}$ & 1.18 & 0.79 & 1.74 & 0.420 & 1.14 & 0.76 & 1.69 & 0.535 & 1.25 & 0.70 & 2.23 & 0.445 & 1.25 & 0.70 & 2.25 & 0.453 \\
\hline 7 & $\begin{array}{c}\text { As a continuous ( } \mathrm{LnHF}) \\
\text { As a categorical }\end{array}$ & 0.91 & 0.79 & 1.04 & 0.176 & 0.93 & 0.81 & 1.06 & 0.283 & 0.84 & 0.69 & 1.03 & 0.098 & 0.84 & 0.68 & 1.04 & 0.112 \\
\hline 8 & $\begin{array}{l}\text { variable: } \mathrm{HF} \\
\text { ( } \leq 168 \text { vs. }>168)\end{array}$ & 1.05 & 0.72 & 1.54 & 0.786 & 1.07 & 0.72 & 1.58 & 0.743 & 0.98 & 0.58 & 1.67 & 0.949 & 1.00 & 0.58 & 1.71 & 0.996 \\
\hline 9 & As a continuous (LnLF/HF) & 0.90 & 0.76 & 1.06 & 0.212 & 0.94 & 0.80 & 1.11 & 0.486 & 0.93 & 0.73 & 1.18 & 0.541 & 0.93 & 0.72 & 1.19 & 0.544 \\
\hline
\end{tabular}

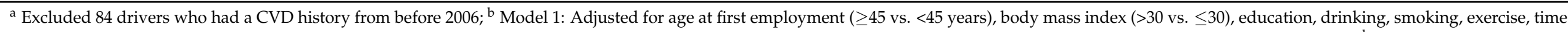

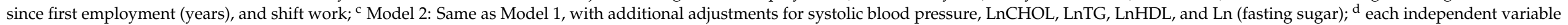
(1-20) was separately included in the models. 
Table 3. Hazard ratios and 95\% confidence intervals for cardiovascular events by HRV index in the Scheme $704{ }^{\mathrm{a}}$.

\begin{tabular}{|c|c|c|c|c|c|c|c|c|c|c|c|c|c|c|c|c|c|c|}
\hline \multirow[b]{3}{*}{ Model 1 b } & \multirow[b]{3}{*}{1} & \multirow{3}{*}{$\begin{array}{l}\text { Independent Variables }{ }^{\mathbf{d}} \\
\text { As a continuous (LnSDNN) }\end{array}$} & \multicolumn{4}{|c|}{$\begin{array}{c}\text { Cardiovascular Disease } \\
\text { (Not Including Hypertensive } \\
\text { Disease) }\end{array}$} & \multicolumn{4}{|c|}{ Hypertensive Disease } & \multicolumn{4}{|c|}{$\begin{array}{l}\text { Ischemic Heart } \\
\text { Disease }\end{array}$} & \multicolumn{4}{|c|}{$\begin{array}{l}\text { Congestive Heart Failure } \\
\text { (CHF) }\end{array}$} \\
\hline & & & \multirow{2}{*}{$\begin{array}{l}\text { HR } \\
1.44\end{array}$} & \multicolumn{2}{|c|}{$95 \%$ CI } & \multirow{2}{*}{$\begin{array}{c}\begin{array}{c}p- \\
\text { Value }\end{array} \\
0.423\end{array}$} & \multirow{2}{*}{$\begin{array}{l}\text { HR } \\
0.35\end{array}$} & \multicolumn{2}{|c|}{$95 \%$ CI } & \multirow{2}{*}{$\begin{array}{c}\begin{array}{c}p- \\
\text { Value }\end{array} \\
0.001\end{array}$} & \multirow{2}{*}{$\begin{array}{l}\text { HR } \\
1.12\end{array}$} & \multicolumn{2}{|c|}{$95 \%$ CI } & \multirow{2}{*}{$\begin{array}{c}p- \\
\text { Value }\end{array}$} & \multirow{2}{*}{$\begin{array}{l}\text { HR } \\
2.46\end{array}$} & \multicolumn{2}{|c|}{$95 \%$ CI } & \multirow{2}{*}{$\begin{array}{c}\begin{array}{c}p- \\
\text { Value }\end{array} \\
0.188\end{array}$} \\
\hline & & & & 0.59 & 3.55 & & & 0.19 & 0.66 & & & 0.35 & 3.54 & & & 0.64 & 9.42 & \\
\hline & 2 & $\begin{array}{c}\text { As a categorical } \\
\text { variable: } \\
\text { SDNN ( } \leq 30 \text { vs. }>30)\end{array}$ & 1.61 & 0.64 & 4.05 & 0.316 & 1.99 & 1.03 & 3.84 & 0.039 & 1.36 & 0.45 & 4.14 & 0.584 & 1.96 & 0.35 & 10.95 & 0.441 \\
\hline & 3 & As a continuous (LnRMSSD) & 2.06 & 1.01 & 4.21 & 0.048 & 0.54 & 0.31 & 0.92 & 0.024 & 2.02 & 0.81 & 5.03 & 0.133 & 2.92 & 0.92 & 9.29 & 0.069 \\
\hline & 4 & $\begin{array}{c}\text { As a categorical } \\
\text { variable: RMSSD }(\leq 20 \text { vs. }>20)\end{array}$ & 0.80 & 0.34 & 1.91 & 0.615 & 1.87 & 0.94 & 3.70 & 0.074 & 0.64 & 0.23 & 1.79 & 0.392 & 0.82 & 0.18 & 3.71 & 0.795 \\
\hline & 5 & As a continuous (LnLF) & 1.05 & 0.73 & 1.51 & 0.783 & 0.76 & 0.59 & 0.97 & 0.027 & 0.96 & 0.61 & 1.50 & 0.855 & 1.30 & 0.64 & 2.66 & 0.470 \\
\hline & 6 & $\begin{array}{l}\text { As a categorical } \\
\quad \text { variable: } \mathrm{LF} \\
(\leq 380 \text { vs. }>380)\end{array}$ & 1.01 & 0.36 & 2.80 & 0.988 & 1.31 & 0.62 & 2.74 & 0.479 & 1.13 & 0.31 & 4.11 & 0.852 & 0.42 & 0.07 & 2.73 & 0.366 \\
\hline & 7 & As a continuous (LnHF) & 0.99 & 0.69 & 1.42 & 0.971 & 0.73 & 0.57 & 0.94 & 0.015 & 1.15 & 0.73 & 1.80 & 0.543 & 0.90 & 0.45 & 1.80 & 0.764 \\
\hline & 9 & As a continuous (LnLF/HF) & 1.09 & 0.71 & 1.67 & 0.708 & 1.04 & 0.77 & 1.42 & 0.786 & 0.78 & 0.47 & 1.32 & 0.358 & 1.70 & 0.72 & 4.00 & 0.228 \\
\hline & 10 & $\begin{array}{l}\text { As a categorical } \\
\text { variable: } \mathrm{LF} / \mathrm{HF} \\
(\leq 3.5 \text { vs. }>3.5)\end{array}$ & 0.95 & 0.40 & 2.26 & 0.901 & 1.02 & 0.56 & 1.85 & 0.954 & 1.34 & 0.42 & 4.28 & 0.621 & 0.77 & 0.17 & 3.53 & 0.740 \\
\hline
\end{tabular}


Table 3. Cont.

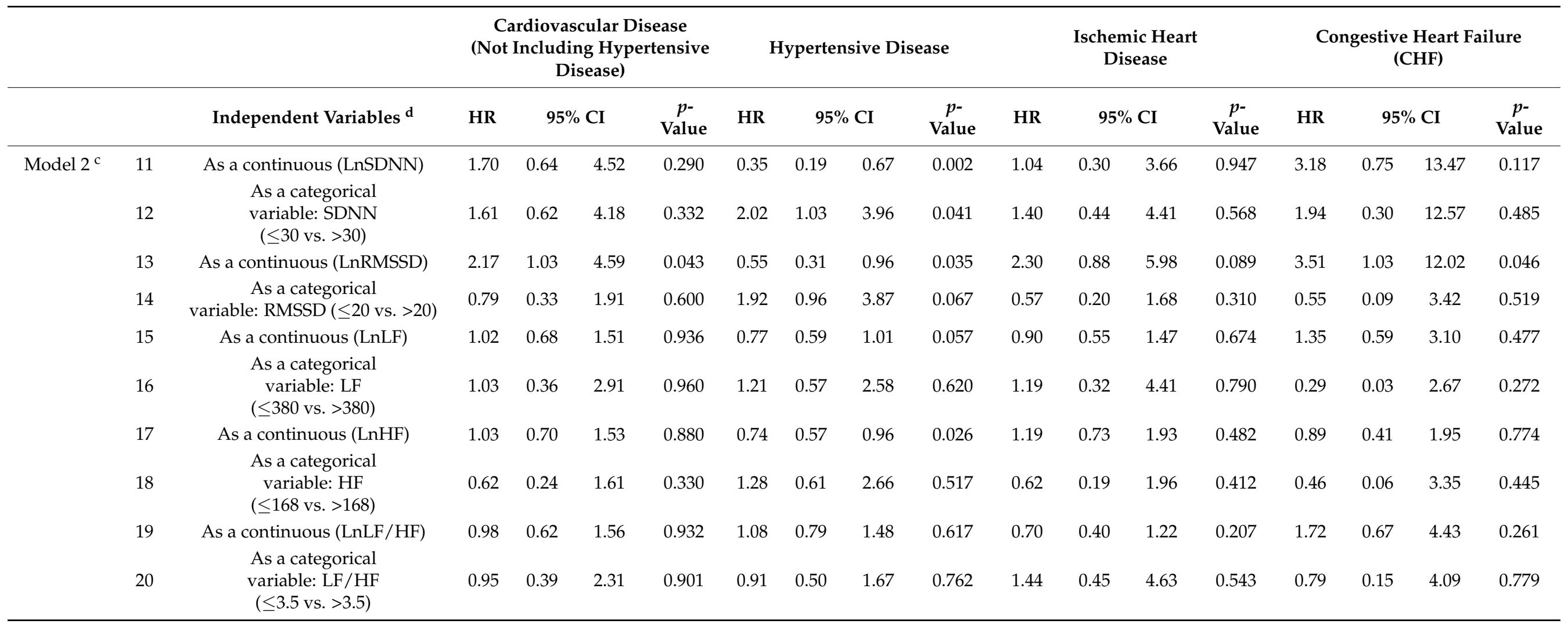

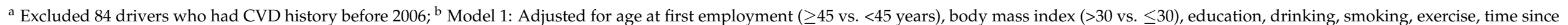

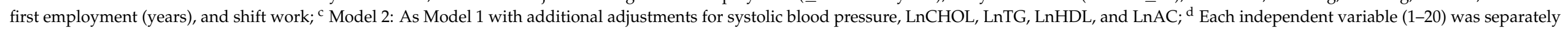
included in the models. 
Similar to the aforementioned findings, among the 704 drivers without a known CVD history at baseline, the SDNN index continued to exhibit a statistically significant association with the risk of CVD. In Model 2, a single unit increment in Ln SDNN was associated with a decrease of $44 \%$ in the hazard for CVD, with adjustments for demographics, working characteristics, and clinical risk factors $(95 \% \mathrm{CI}=0.34-0.95, p=0.031)$. Regarding the dichotomized approach with a median split, a low SDNN was associated with a hazard ratio of 1.83 (95\% CI = 1.10-3.04) in Model 1 and 1.87 (95\% CI = 1.11-3.13) in Model 2. Furthermore, the LF index exhibited associations with the risk of CVD in the continuous approach in both models.

\subsection{HRV Indices and 8 Year Cardiovascular Diagnostic Risk Categories}

Table 3 and Table S3 list the hazard ratios of HRV indices for cardiovascular diagnostic categories among the different driver groups with or without a known CVD history at baseline. After we excluded 84 cases of prevalent CVD before 2006 (Table 3), we found that the SDNN index was associated with increased risks of hypertensive disease in both the continuous and dichotomized approaches. A single unit increment in Ln SDNN was associated with a decrease of $65 \%$ in hypertensive disease in both models (Model 1: $95 \%$ CI $=0.19-0.66, p=0.001$; Model 2: 95\% CI $=0.19-0.67 ; p=0.002$ ). Low levels of SDNN (0-30) were associated with increased risks of hypertensive disease in both models (Model 1: hazard ratio $=1.99 ; 95 \% \mathrm{CI}=1.03-3.84 ; p=0.039$; Model 2: hazard ratio $=2.02$; 95\% CI $=1.03-3.96 ; p=0.041$ ).

Meanwhile, a single unit increment in Ln RMSSD was associated with a decrease of $45-46 \%$ in hypertensive disease in the two models (Model 1: hazard ratio $=0.54$; $95 \% \mathrm{CI}=0.31-0.92, p=0.024$; Model 2: hazard ratio $=0.55 ; 95 \% \mathrm{CI}=0.31-0.96 ; p=0.035$ ).

A single unit increment in Ln HF was associated with a decrease of $26-27 \%$ in hypertensive disease in two models (Model 1: hazard ratio $=0.73 ; 95 \% \mathrm{CI}=0.57-0.94, p=0.015$; Model 2: hazard ratio $=0.74 ; 95 \% \mathrm{CI}=0.57-0.96 ; p=0.026$ ). $\mathrm{Ln}$ LF had a significant hazard ratio of 0.76 for hypertensive disease in Model $1(95 \% \mathrm{CI}=0.59-0.97 ; p=0.027)$, which became nonsignificant in Model 2.

For CHF, Ln RMSSD only had a significant hazard ratio of 3.51, for which in Model 2: $95 \% \mathrm{CI}=1.03-12.0 ; p=0.046$.

\section{Discussion}

This study used a prospective professional cohort study to investigate the relationship between HRV and the risk of CVD in professional drivers without known CVD. The major finding of this study was that the SDNN and LF levels are useful for predicting the 8 year CVD risk even when adjusting for CVD risk factors. Furthermore, increased SDNN and LF levels elevated the risks for other CVD events, such as hypertensive disease.

Each unit increment in Ln SDNN was associated with a decrease of $65 \%$ in hypertensive disease in Model $2(95 \% \mathrm{CI}=0.19-0.67, p=0.002)$. Our results are consistent with a meta-analysis that indicated that the predicted risks of incident CVD of the 10th and 19th percentiles in SDNN compared with the 50th percentile were $1.50(95 \% \mathrm{CI}=1.22,1.83)$ and $0.67(95 \% \mathrm{CI}=0.41,1.09)$, respectively [36]. In general, the SDNN is the gold standard for the medical stratification of cardiac risk and predicts both CVD morbidity and mortality. However, this only applies when recorded over a $24 \mathrm{~h}$ period.

Furthermore, this study observed that the LF index was associated with the risk of CVD and hypertensive disease in a continuous approach. While sitting upright during resting conditions, the LF reflected parasympathetic nervous system activity and baroreflex activity, not sympathetic nervous system activity and cardiac sympathetic innervation [22]. A previous study demonstrated that a higher occupational workload resulted in reduced LF power, which indicates that a high workload is related to attenuating cardiac autonomic modulation during sleep. In contrast, enhanced sympathetic baroreceptor cardiac regulation during sleep in workers with a high level of physical leisure time activity was 
observed [37]. Bus drivers have a high workload and less leisure-time activity, which leads to the development of CVDs; thus, low LF power is reflected in advance.

Additionally, drivers with a low HRV may already suffer from silent CVD. Numerous overlapping risk factors exist for reduced HRV and CVD events [38]. However, the causal relationship of risk factors with the development of CVD or reduced HRV is still not completely understood. Work stress is associated with both CVD and reduced HRV [39]; however, we do not yet know whether work stress affects the development of CVD more than it contributes to reduced HRV. Further investigating the associations between psychosocial risk factors and HRV indices would be worthwhile [40,41]. Psychosocial conditions such as work stress, stressful life events, and mood disorders are emerging risk factors for CVD [42]. Risk factors are preceded by indicators of decreased vagal function; therefore, HRV was found to be a useful tool for studying work-related stress and the accompanying physiological effects. The SDNN was reported to be significantly lower among those categorized into a high-job-strain group than among those categorized into a low-job-strain group [43]. Amelsvoort [39] reported that a decreased SDNN level in shift workers indicates less favorable cardiovascular autonomic regulation. Moreover, numerous studies have indicated that a chronic autonomic imbalance with sympathetic dominance may partially explain the effects of work stress on CVD events [21]. Therefore, HRV could be used to screen workers at high risk of CVD, and preventive measures could be taken in advance.

This study had several advantages that included the large bus drivers cohort, the prospective design, the noninvasive marker of 5 min HRV measurements, confounders' adjustment, and comprehensive CVD data collection. In addition, we fully admit that the method of this study has some limitations. First, only male bus drivers were included, which restricts the generalization of the results to females. Second, HRV may be influenced by the severity of CVD, respiratory patterns, circadian rhythm, as well as by the use of $\beta$-blockers or antidepressants [44-47]. Thus, analyses should be further stratified by the severity of diseases, such as MI or revascularization, as well as by ICD-10-PCS (Procedure Codes). In addition, a history of diabetes, cognitive disorders, severe lung diseases, and the use of $\beta$-blockers and antidepressants must be considered. Third, the current study design could not clarify which risk factors contributed more to reduced HRV and CVD events so that preventive measures can be taken in advance. The small number of subjects in these sub-categories is a restriction of this study. The statistical power may be too small to generalize the results to other subjects. Fourth, there is a possibility that the high false positive rate in this study could have caused incorrect results. Therefore, we used the strict criteria that CVD cases had to have at least five visits for the same diagnosis within 1 year, or were an inpatient with one or more admissions during the study period based on a clinical physician's suggestion. This increased the sensitivity and decreased the specificity for CVD, but it could have underestimated the effect of our final result. Lastly, and most importantly, this study directly used commercial instruments and automated programs to analyze the change in heart rate during the short term by the method of time domain and frequency domain with an ANS Analyzer. This may obscure some meaningful signals in heart rate for arrhythmias or other CVD diseases. With the technological advances in big data analytics, a future study should be attempted to identify and interpret the computer identification of segments with aberrant patterns for CVD diseases.

In conclusion, this professional drivers' cohort study concluded that the HRV parameters SDNN and LF are independent predictors of CVD and hypertensive disease, even after adjusting for risk factors. Further research is required to determine the preventive measures for modifying HRV dysfunction, as well as to investigate whether these interventions could reduce CVD risk in professional drivers. 
Supplementary Materials: The following are available online at https:/ / www.mdpi.com/article/ 10.3390/ijerph182111486/s1, Figure S1: Taiwan Bus Driver Cohort Study (TBDCS) schedule diagram, Table S1: Definition of HRV measures, Table S2: Compared HRV index for cardiovascular diagnostic categories in study population $(n=788)$, Table S3: Hazard ratios and $95 \%$ confidence intervals for cardiovascular diagnostic categories by HRV index in the study population $(n=788)$.

Author Contributions: Y.-C.W. designed the research, collected data, engaged in drafting the manuscript, and revised it critically. W.-T.W. conducted data collection and data analysis and interpretation, and helped to draft the manuscript and revise it critically. C.-C.W. collected data and participated in data analysis. Y.-H.Y. participated in data analysis, review, and editing. W.-T.W. conceived the study, participated in its design and coordination, and helped to draft the manuscript. All authors have read and agreed to the published version of the manuscript.

Funding: The National Health Research Institutes of Taiwan (grants 98-EO-PP01, 99-EO-PP01, 00-EO-PP01, EO-101-PP-01, EO-102-PP-01, and EO-103-PP-01), and the Institute of Occupational Safety and Health of Taiwan (grants IOSH96-M102 and IOSH97-M102) supported this study. The funders had no role in the research design, data collection and analysis, manuscript preparation, or publication decision.

Institutional Review Board Statement: The study was conducted according to the guidelines of the Declaration of Helsinki, and approved by the Institutional Review Board of National Health Research Institutes (NIRB File Number: EC1060516-E).

Informed Consent Statement: The Institutional Review Board of the National Health Research Institutes, Taiwan, approved this study (NIRB File Number: EC1060516-E). The composition and operation of the review committee are established in accordance with the ICH-GCP guidelines. The authors confirm that all experiments were performed in accordance with relevant guidelines and regulations. After explaining the content in detail, informed consent was obtained from each participant.

Data Availability Statement: The data are not available, because we did not inform the participants of the data transparency nor declare the possibility on the institutional review board.

Acknowledgments: The authors are very grateful to the late Saou-Hsing Liou for his contribution to this article. All authors thank the drivers and administrators at the bus company for their participation and cooperation. The current analysis was based on data provided by the Collaboration Center of Health Information Application, Ministry of Health and Welfare, Executive Yuan, Taiwan.

Conflicts of Interest: The authors declare no conflict of interests.

\section{Abbreviations}

$\begin{array}{ll}\text { HRV } & \text { heart rate variability } \\ \text { TBDCS } & \text { Taiwan Bus Driver Cohort Study } \\ \text { CVD } & \text { cardiovascular disease } \\ \text { SDNN } & \text { standard deviation of N-N intervals } \\ \text { LF } & \text { low frequency } \\ \text { RMSSD } & \text { root-mean-square of the successive differences } \\ \text { HF } & \text { high frequency } \\ \text { MI } & \text { myocardial infarction } \\ \text { IHD } & \text { ischemic heart disease } \\ \text { CHD } & \text { coronary heart disease } \\ \text { ANS } & \text { autonomic nervous system } \\ \text { NHIRD } & \text { Taiwan's National Health Insurance Research Database } \\ \text { ICH-GCP } & \text { International Conference on Harmonization-Good Clinical Practice } \\ \text { CHF } & \text { congestive heart failure } \\ \text { VLF } & \text { very low frequency } \\ \text { TP } & \text { total power } \\ \text { PSI } & \text { physical stress index } \\ \text { CHOL } & \text { total cholesterol }\end{array}$




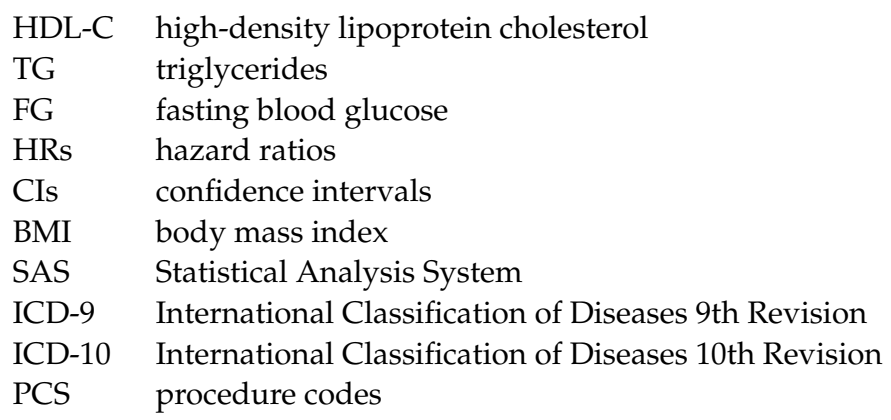

\section{References}

1. Hwang, W.J.; Hong, O. Work-related cardiovascular disease risk factors using a socioecological approach: Implications for practice and research. Eur. J. Cardiovasc. Nurs. 2012, 11, 114-126. [CrossRef]

2. World Health Organization. Cardiovascular Diseases (CVDs). 2021. Available online: https://www.who.int/news-room/factsheets / detail/cardiovascular-diseases-(cvds) (accessed on 11 June 2021).

3. Tse, J.L.M.; Flin, R.; Mearns, K. Bus driver well-being review: 50 years of research. Transport. Res. F-Traf. 2006, 9, 89-114. [CrossRef]

4. $\quad$ Bigert, C.; Gustavsson, P.; Hallqvist, J.; Hogstedt, C.; Lewne, M.; Plato, N.; Reuterwall, C.; Schéele, P. Myocardial infarction among professional drivers. Epidemiology 2003, 14, 333-339. [CrossRef]

5. Netterstrom, B.; Juel, K. Impact of Work-Related and Psychosocial Factors on the Development of Ischemic Heart-Disease among Urban Bus Drivers in Denmark. Scand. J. Work Environ. Health 1988, 14, 231-238. [CrossRef]

6. Hartvig, P.; Midttun, O. Coronary heart disease risk factors in bus and truck drivers. A controlled cohort study. Int. Arch. Occup. Environ. Health. 1983, 52, 353-360. [CrossRef]

7. Tuchsen, F.; Hannerz, H.; Roepstorff, C.; Krause, N. Stroke among male professional drivers in Denmark, 1994-2003. Occup. Environ. Med. 2006, 63, 456-460. [CrossRef]

8. $\quad$ Chen, C.C.; Shiu, L.J.; Li, Y.L.; Tung, K.Y.; Chan, K.Y.; Yeh, C.J.; Chen, S.C.; Wong, R.H. Shift Work and Arteriosclerosis Risk in Professional Bus Drivers. Ann. Epidemiol. 2010, 20, 60-66. [CrossRef]

9. Gimeno, D.; Benavides, F.G.; Mira, M.; Martinez, J.M.; Benach, J. External validation of psychological job demands in a bus driver sample. J. Occup. Health 2004, 46, 43-48. [CrossRef]

10. Wang, P.D.; Lin, R.S. Coronary heart disease risk factors in urban bus drivers. Public Health 2001, 115, 261-264. [CrossRef]

11. Tsai, S.S.; Lai, C.H.; Shih, T.S.; Lin, M.H.; Liou, S.H. High job strain is associated with inflammatory markers of disease in young long-haul bus drivers. J. Occup. Health Psychol. 2014, 19, 336. [CrossRef]

12. Von Borell, E.; Langbein, J.; Despres, G.; Hansen, S.; Leterrier, C.; Marchant-Forde, J.; Marchant-Forde, R.; Minero, M.; Mohr, E.; Prunier, A.; et al. Heart rate variability as a measure of autonomic regulation of cardiac activity for assessing stress and welfare in farm animals-A review. Physiol. Behav. 2007, 92, 293-316. [CrossRef] [PubMed]

13. Cowan, M.J. Measurement of Heart-Rate-Variability. West. J. Nurs. Res. 1995, 17, 32-48. [CrossRef] [PubMed]

14. Liao, D.P.; Barnes, R.W.; Chambless, L.E.; Simpson, R.J.; Sorlie, P.; Heiss, G. Age, Race, and Sex-Differences in Autonomic CardiacFunction Measured by Spectral-Analysis of Heart-Rate-Variability-The Aric Study. Am. J. Cardiol. 1995, 76, 906-912. [CrossRef]

15. Tsuji, H.; Venditti, F.J.; Manders, E.S.; Evans, J.C.; Larson, M.G.; Feldman, C.L.; Levy, D. Determinants of heart rate variability. J. Am. Coll. Cardiol. 1996, 28, 1539-1546. [CrossRef]

16. Berntson, G.G.; Bigger, J.T.; Eckberg, D.L.; Grossman, P.; Kaufmann, P.G.; Malik, M.; Nagaraja, H.N.; Porges, S.W.; Saul, J.P.; Stone, P.H.; et al. Heart rate variability: Origins, methods, and interpretive caveats. Psychophysiology 1997, 34, 623-648. [CrossRef]

17. Greiser, K.H.; Kluttig, A.; Schumann, B.; Swenne, C.A.; Kors, J.A.; Kuss, O.; Haerting, J.; Schmidt, H.; Thiery, J.; Werdan, K. Cardiovascular diseases, risk factors and short-term heart rate variability in an elderly general population: The CARLA study 2002-2006. Eur. J. Epidemiol. 2009, 24, 123-142. [CrossRef] [PubMed]

18. Harris, K.F.; Matthews, K.A. Interactions between autonomic nervous system activity and endothelial function: A model for the development of cardiovascular disease. Psychosom. Med. 2004, 66, 153-164. [CrossRef]

19. Task Force of the European Society of Cardiology and the North American Society of Pacing and Electrophysiology. Heart rate variability: Standards of measurement, physiological interpretation and clinical use. Circulation 1996, 93, 1043-1065.

20. Zheng, Z.H.; Zeng, Y.T.; Wu, J.Y. Increased neuroplasticity may protect against cardiovascular disease. Int. J. Neurosci. 2013, 123, 599-608. [CrossRef]

21. Thayer, J.F.; Ahs, F.; Fredrikson, M.; Sollers, J.J.; Wager, T.D. A meta-analysis of heart rate variability and neuroimaging studies: Implications for heart rate variability as a marker of stress and health. Neurosci. Biobehav. R. 2012, 36, 747-756. [CrossRef]

22. Shaffer, F.; Ginsberg, J.P. An Overview of Heart Rate variability Metrics and Norms. Front. Public Health 2017, 28, 258. [CrossRef]

23. Tsuji, H.; Venditti, F.J.; Manders, E.S.; Evans, J.C.; Larson, M.G.; Feldman, C.L.; Levy, D. Reduced Heart-Rate-Variability and Mortality Risk in an Elderly Cohort-The Framingham Heart-Study. Circulation 1994, 90, 878-883. [CrossRef]

24. Bilchick, K.C.; Fetics, B.; Djoukeng, R.; Fisher, S.G.; Fletcher, R.D.; Singh, S.N.; Nevo, E.; Berger, R.D. Prognostic value of heart rate variability in chronic congestive heart failure (veterans affairs' survival trial of antiarrhythmic therapy in congestive heart failure). Am. J. Cardiol. 2002, 90, 24-28. [CrossRef] 
25. Dekker, J.M.; Schouten, E.G.; Klootwijk, P.; Pool, J.; Swenne, C.A.; Kromhout, D. Heart rate variability from short electrocardiographic recordings predicts mortality from all causes in middle-aged and elderly men-The zutphen study. Am. J. Epidemiol. 1997, 145, 899-908. [CrossRef]

26. La Rovere, M.T.; Bigger, J.T.; Marcus, F.I.; Mortara, A.; Schwartz, P.J.; Investigators, A. Baroreflex sensitivity and heart-rate variability in prediction of total cardiac mortality after myocardial infarction. Lancet 1998, 351, 478-484. [CrossRef]

27. Papaioannou, V.; Pneumatikos, I.; Maglaveras, N. Association of heart rate variability and inflammatory response in patients with cardiovascular diseases: Current strengths and limitations. Front. Physiol. 2013, 4, 174. [CrossRef]

28. Janszky, I.; Ericson, M.; Mittleman, M.A.; Wamala, S.; Al-Khalili, F.; Schenck-Gustafsson, K.; Orth-Gomer, K. Heart rate variability in long-term risk assessment in middle-aged women with coronary heart disease: The Stockholm Female Coronary Risk Study. J. Intern. Med. 2004, 255, 13-21. [CrossRef]

29. Stein, P.K.; Barzilay, J.I.; Chaves, P.H.M.; Mistretta, S.Q.; Domitrovich, P.P.; Gottdiener, J.S.; Rich, M.W.; Kleiger, R.E. Novel Measures of Heart Rate Variability Predict Cardiovascular Mortality in Older Adults Independent of Traditional Cardiovascular Risk Factors: The Cardiovascular Health Study (CHS). J. Cardiovasc. Electr. 2008, 19, 1169-1174. [CrossRef]

30. Fyfe-Johnson, A.L.; Muller, C.J.; Alonso, A.; Folsom, A.R.; Gottesman, R.F.; Rosamond, W.D.; Whitsel, E.A.; Agarwal, S.K.; MacLehose, R.F. Heart Rate Variability and Incident Stroke The Atherosclerosis Risk in Communities Study. Stroke 2016, 47, 1452-1458. [CrossRef]

31. Dekker, J.M.; Crow, R.S.; Folsom, A.R.; Hannan, P.J.; Liao, D.; Swenne, C.A.; Schouten, E.G. Low heart rate variability in a 2-minute rhythm strip predicts risk of coronary heart disease and mortality from several causes-The ARIC study. Circulation 2000, 102, 1239-1244. [CrossRef]

32. Leino, J.; Virtanen, M.; Kahonen, M.; Nikus, K.; Lehtimaki, T.; Koobi, T.; Lehtinen, R.; Turjanmaa, V.; Viik, J.; Nieminen, T. Exercise-test-related heart rate variability and mortality The Finnish cardiovascular study. Int. J. Cardiol. 2010, 144, 154-155. [CrossRef] [PubMed]

33. Weber, C.S.; Thayer, J.F.; Rudat, M.; Wirtz, P.H.; Zimmermann-Viehoff, F.; Thomas, A.; Perschel, F.H.; Arck, P.C.; Deter, H.C. Low vagal tone is associated with impaired post stress recovery of cardiovascular, endocrine, and immune markers. Eur. J. Appl. Physiol. 2010, 109, 201-211. [CrossRef]

34. Wu, W.T.; Tsai, S.S.; Liao, H.Y.; Lin, Y.J.; Lin, M.H.; Wu, T.N.; Shih, T.S.; Liou, S.H. Usefulness of overnight pulse oximeter as the sleep assessment tool to assess the 6-year risk of road traffic collision: Evidence from the Taiwan Bus Driver Cohort Study. Int. J. Epidemiol. 2017, 46, 266-277. [CrossRef]

35. Wu, W.T.; Wang, C.C.; Liou, S.H. Effects of nanoparticles exposure and PON1 genotype on heart rate variability. Environ. Res. 2019, 176, 108377. [CrossRef]

36. Hillebrand, S.; Gast, K.B.; de Mutsert, R.; Swenne, C.A.; Jukema, J.W.; Middeldorp, S.; Rosendaal, F.R.; Dekkers, O.M. Heart rate variability and first cardiovascular event in populations without known cardiovascular disease: Meta-analysis and dose-response meta-regression. Europace 2013, 15, 742-749. [CrossRef]

37. Hallman, D.M.; Jorgensen, M.B.; Holtermann, A. On the health paradox of occupational and leisure-time physical activity using objective measurements: Effects on autonomic imbalance. PLoS ONE 2017, 12, e0177042. [CrossRef] [PubMed]

38. Thayer, J.F.; Yamamoto, S.S.; Brosschot, J.F. The relationship of autonomic imbalance, heart rate variability and cardiovascular disease risk factors. Int. J. Cardiol. 2010, 141, 122-131. [CrossRef]

39. Van Amelsvoort, L.G.P.M.; Schouten, E.G.; Maan, A.C.; Swenne, C.A.; Kok, F.J. Occupational determinants of heart rate variability. Int. Arch. Occup. Environ. Health 2000, 73, 255-262. [CrossRef]

40. Solarikova, P.; Turonova, D.; Brezina, I.; Rajčáni, J. Heart rate variability in psychosocial stress: Comparison between laboratory and real-life setting. Act. Nerv. Super. Rediviva 2016, 58, 77-82.

41. Lischke, A.; Jacksteit, R.; Mau-Moeller, A.; Pahnke, R.; Hamm, A.O.; Weippert, M. Heart rate variability is associated with psychosocial stress in distinct social domains. J. Psychosom. Res. 2018, 106, 56-61. [CrossRef]

42. Mulle, J.G.; Vaccarino, V. Cardiovascular Disease, Psychosocial Factors, and Genetics: The Case of Depression. Prog. Cardiovasc. Dis. 2013, 55, 557-562. [CrossRef]

43. Hernandez-Gaytan, S.I.; Rothenberg, S.J.; Landsbergis, P.; Becerril, L.C.; De Leon-Leon, G.; Collins, S.M.; Díaz-Vásquez, F.J. Job Strain and Heart Rate Variability in Resident Physicians Within a General Hospital. Am. J. Ind. Med. 2013, 56, 38-48. [CrossRef] [PubMed]

44. Fang, Y.; Sun, J.T.; Li, C.; Poon, C.S.; Wu, G.Q. Effect of Different Breathing Patterns on Nonlinearity of Heart Rate Variability. In Proceedings of the Annual International Conference of the IEEE Engineering in Medicine and Biology Society, Vancouver, BC, Canada, 20-25 August 2008; pp. 3220-3223. [CrossRef]

45. Aronson, D.; Burger, A.J. Effect of beta-blockade on heart rate variability in decompensated heart failure. Int. J. Cardiol. 2001, 79, 31-39. [CrossRef]

46. O’Regan, C.; Kenny, R.A.; Cronin, H.; Finucane, C.; Kearney, P.M. Antidepressants strongly influence the relationship between depression and heart rate variability: Findings from The Irish Longitudinal Study on Ageing (TILDA). Psychol. Med. 2015, 45, 623-636. [CrossRef]

47. Collins, S.; Karasek, R. Reduced vagal cardiac control variance in exhausted and high strain job subjects. Int. J. Occup. Med. Environ. Health 2010, 23, 267-278. [CrossRef] [PubMed] 